\title{
ENSO surface longwave radiation forcing over the tropical Pacific
}

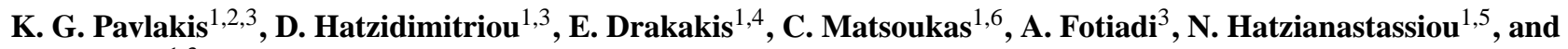 \\ I. Vardavas ${ }^{1,3}$ \\ ${ }^{1}$ Foundation for Research and Technology-Hellas, Heraklion, Crete, Greece \\ ${ }^{2}$ Department of General Applied Science, Technological Educational Institute of Crete, Greece \\ ${ }^{3}$ Department of Physics, University of Crete, Crete, Greece \\ ${ }^{4}$ Department of Electrical Engineering, Technological Educational Institute of Crete, Greece \\ ${ }^{5}$ Laboratory of Meteorology, Department of Physics, University of Ioannina, Greece \\ ${ }^{6}$ Department of Environment, University of the Aegean, Greece
}

Received: 25 July 2006 - Published in Atmos. Chem. Phys. Discuss.: 11 December 2006

Revised: 22 February 2007 - Accepted: 2 April 2007 - Published: 24 April 2007

\begin{abstract}
We have studied the spatial and temporal variation of the surface longwave radiation (downwelling and net) over a 21-year period in the tropical and subtropical Pacific Ocean ( $40 \mathrm{~S}-40 \mathrm{~N}, 90 \mathrm{E}-75 \mathrm{~W})$. The fluxes were computed using a deterministic model for atmospheric radiation transfer, along with satellite data from the ISCCP-D2 database and reanalysis data from NCEP/NCAR (acronyms explained in main text), for the key atmospheric and surface input parameters. An excellent correlation was found between the downwelling longwave radiation (DLR) anomaly and the Niño-3.4 index time-series, over the Niño-3.4 region located in the central Pacific. A high anti-correlation was also found over the western Pacific (15-0 S, 105-130E). There is convincing evidence that the time series of the mean downwelling longwave radiation anomaly in the western Pacific precedes that in the Niño-3.4 region by $3-4$ months. Thus, the downwelling longwave radiation anomaly is a complementary index to the SST anomaly for the study of ENSO events and can be used to asses whether or not El Niño or La Niña conditions prevail. Over the Niño-3.4 region, the mean DLR anomaly values range from $+20 \mathrm{Wm}^{-2}$ during El Niño episodes to $-20 \mathrm{Wm}^{-2}$ during La Niña events, while over the western Pacific (15-0 S, 105-130 E) these values range from $-15 \mathrm{Wm}^{-2}$ to $+10 \mathrm{Wm}^{-2}$, respectively. The long- term average (1984-2004) distribution of the net downwelling longwave radiation at the surface over the tropical and subtropical Pacific for the three month period NovemberDecember-January shows a net thermal cooling of the ocean surface. When El Niño conditions prevail, the thermal radiative cooling in the central and south-eastern tropical Pacific becomes weaker by $10 \mathrm{Wm}^{-2}$ south of the equator in the cen-
\end{abstract}

Correspondence to: K. Pavlakis

(pavlakis@iesl.forth.gr) tral Pacific (7-0 S, 160-120 W) for the three-month period of NDJ, because the DLR increase is larger than the increase in surface thermal emission. In contrast, the thermal radiative cooling over Indonesia is enhanced by $10 \mathrm{Wm}^{-2}$ during the early (August-September-October) El Niño phase.

\section{Introduction}

The El Niño Southern Oscillation (ENSO) is a natural cycle that couples the ocean-atmosphere system over the tropical Pacific and operates on a timescale of 2-7 years. Once developed, it causes a shift in the seasonal temperature and precipitation patterns in many different regions of the world, since heating of the tropical atmosphere creates changes in the global atmospheric circulation. Thus, ENSO is a dominant source of inter-annual climate variability around the world. Following the early work of Bjerknes $(1966,1969)$ who attributed ENSO to coupled Pacific ocean-atmosphere interactions, the dynamics of this pattern of climate variability was extensively studied by many workers (e.g. Philander, 1990; McCreary and Anderson, 1991; Neelin et al., 1998). Normally, the equatorial Pacific Ocean is characterized by warm waters in the west and cold waters in the east. The ENSO warm phase (El Niño) is associated with an unusual warming of the eastern and central equatorial Pacific accompanied by a shift in the deep atmospheric convection from the western Pacific to the equatorial central Pacific. La Niña, the ENSO cold phase, is the counterpart to El Niño, often following it. It is characterised by cooler than normal sea surface temperatures across the equatorial eastern Pacific and a strengthening of near ocean-surface winds travelling from east to west. Thus ENSO is an oscillation between warm

Published by Copernicus GmbH on behalf of the European Geosciences Union. 
and cold events with a peak that typically occurs late in the calendar year (late December-early January). Both El Niño and La Niña events last for about a year, but they can last for as long as 18 months (see the recent review by Wang and Fiedler, 2006). Over the past two decades a large number of studies have appeared, attempting to explain the mechanism of the oscillation between the two phases of the ENSO phenomenon and many models have been proposed (e.g. Suarez and Schopf, 1988; Cane et al., 1990; Jin, 1997a, b; Picaut et al., 1997; Wang et al., 1999; Wang, 2001). A recent short review summarizing theories and mechanisms about El Niño variability is given by Dijkstra (2006).

During ENSO, a feedback between atmospheric and ocean properties is observed. Sea surface temperature (SST) anomalies induce wind stress anomaly patterns that in turn produce a positive feedback on the SST. Variation of the above properties cause significant changes in other oceanic and atmospheric variables, e.g. the mean depth of the thermocline, the water vapour content of the atmosphere and the relative distributions of low, middle and high clouds. Water vapour and clouds are the main regulators of the radiative heating of the planet since changes in these parameters modulate the variability in the radiation fluxes that regulate the heating or cooling of the Earth's surface and atmosphere (Tian and Ramanathan, 2002). The radiation field in turn, influences SST and atmospheric water vapour. Thus ENSO involves complex climatic processes and feedbacks that make its onset time, duration, strength and spatial structure difficult to predict (see Fedorov et al., 2003, and references therein). International monitoring programmes of the coupled atmosphere-ocean system started in the Pacific around 1985 and led to the TAO/TRITON (Tropical Atmosphere Ocean project/Triangle Trans Ocean Buoy Network) array of moored buoys. The aim of this programme is to provide real-time measurements of winds, sea surface temperature, subsurface temperature, sea level and ocean flow that help in the understanding of the physical processes responsible for ENSO (McPhaden et al., 1998).

The variability and the spatial distribution of the ocean and atmospheric variables are not the same for all ENSO events. Thus a definition of ENSO is necessary for the study of this phenomenon (Trenberth, 1997). The phase and strength of ENSO events are defined by an index. Several different indices have been used in the literature, mostly based on SST, although there is one index, the Southern Oscillation index, which is related to air pressure differences at sea level, between Darwin (Australia) in the west and Tahiti in the east. The SST based indices are obtained from the SST anomalies with respect to average values over some specified region of the ocean (see for example, Trenberth and Stepaniak, 2000; Hanley et al., 2003). There has been also an effort to combine several atmospheric-oceanic variables into a single index like the multivariate ENSO index (Wolter and Timlin, 1998). Averages of $850 \mathrm{mb}$ wind, outgoing longwave radiation (OLR) at the top of the atmosphere as well as precipitation over spe- cific regions (Curtis and Adler, 2000) are also used, although not often, to monitor ENSO.

The Earth's climate system is driven by the radiative energy balance between the solar shortwave radiation (SW) absorbed by the atmosphere and the surface of the Earth and the thermal longwave radiation ( $\mathrm{LW}$ ) emitted by the Earth to space. In this respect, ENSO events are expected to be associated with the spatial and temporal variability of the radiative energy balance over the tropical and subtropical Pacific. The net heat flux into the ocean plays a key role in ENSO evolution and is a significant variable in the models that have been developed to make ENSO predictions (Dijkstra, 2006). The variation of the net heat flux during ENSO events is of paramount importance to the dynamics of the system (Harrison et al., 2002; Chou et al., 2004). The net heat flux into the ocean is a small residual of four terms, the downward shortwave radiation at the surface (DSR), the latent heat loss, the sensible heat transfer and the net downwelling longwave radiation at the Earth's surface (NSL). The NSL is the difference between the downward longwave radiation (DLR) at the Earth's surface and the Earth's surface thermal emission. The DLR at the Earth's surface is a very important component of the surface radiation budget with variations arising from increases in greenhouse gases or from changes in other atmospheric properties that occur during ENSO events (Intergovernmental Panel on Climate Change, IPCC, 2001). In this work we shall focus on the behaviour of the DLR and NSL during warm and cold ENSO events over the tropical and subtropical Pacific Ocean. The DLR depends mainly on the vertical distributions of temperature and water vapour in the lower troposphere, as well as on the cloud amounts and cloud radiative properties. We shall show that the DLR is a very useful index for the description of the phase and evolution of ENSO events.

We present DLR and NSL data generated by a deterministic radiation transfer model for the period 1984-2004 for the tropical and subtropical Pacific Ocean and examine their spatial and temporal variability during ENSO events. In addition, we investigate the correlation of DLR and NSL anomalies with the Niño 3.4 index. In Sect. 2 we describe the radiation model and the input data used. In Sect. 3, the surface longwave radiation distribution and its variation during warm and cold ENSO phases are presented. In Sect. 4, the DLR and NSL variation during ENSO evolution is examined. In Sect. 5, the correlation of the Niño 3.4 index and surface radiation parameters are presented while in Sect. 6 a more detailed analysis of radiation parameters in the western Pacific is presented. In Sect. 7, we discuss our results and in Sect. 8 we present our conclusions. Table 1 lists the symbol definitions of the radiation parameters that are most often used in this paper. 


\section{Radiation model and data description}

We use the FORTH deterministic model (Pavlakis et al., 2004) for the radiation transfer of terrestrial infrared radiation, to compute the downward longwave radiation at the surface of the Earth (DLR). This model is based on a detailed radiative-convective model developed for climate change studies (Vardavas and Carver 1984), but modified in order to model the longwave atmospheric radiation fluxes at the Earth's surface and at top of atmosphere (TOA), on a $2.5^{\circ} \times 2.5^{\circ}$ grid for the entire globe.

The model DLR has a temporal resolution of one month, and a vertical resolution (from the surface up to $50 \mathrm{mb}$ ) of $5 \mathrm{mb}$, to ensure that the atmospheric layers are optically thin with respect to the Planck mean longwave opacity. The atmospheric molecules considered are; $\mathrm{H}_{2} \mathrm{O}, \mathrm{CO}_{2}, \mathrm{CH}_{4}, \mathrm{O}_{3}$, and $\mathrm{N}_{2} \mathrm{O}$. The sky is divided into clear and cloudy fractions. The cloudy fraction includes three non-overlapping layers of low, mid and high-level clouds. Expressions for the fluxes for clear and cloudy sky can be found in Hatzianastassiou et al. (1999). The model input data include cloud amounts (for low, mid, high-level clouds), cloud absorption optical depth, cloud-top pressure and temperature (for each cloud type), cloud geometrical thickness and vertical temperature and specific humidity profiles. For the total amount of ozone, carbon dioxide, methane, and nitrous oxide in the atmosphere, we used the same values as in Hatzianastassiou and Vardavas (2001).

All of the cloud climatological data for our radiation transfer model were taken from the International Satellite Cloud Climatology Project (ISCCP-D2) data set (Rossow and Schiffer, 1999), which provides monthly means for 72 climatological variables in 2.5-degree equal-angle gridboxes for the period 1984-2004. The vertical distributions of the temperature and water vapour as well as the surface temperature, were taken from the National Center for Environmental Prediction/National Centers for Atmospheric Research (NCEP/NCAR) reanalysis project (Kistler et al., 2001), corrected for topography as in Hatzianastassiou et al. (2001). These data are also on a 2.5-degree resolution, monthly averaged and cover the same 21 -year period as the ISCCP-D2 data.

A full presentation and discussion of the model and DLR distribution can be found in Pavlakis et al. (2004). There, a series of sensitivity tests were performed to investigate how much uncertainty is introduced in the model DLR by uncertainties in the input parameters, such as air temperature, skin temperature, low, middle or high cloud amount as well as the cloud physical thickness, cloud overlap schemes, and the use of daily-mean instead of monthly-mean input data. The model DLR was also validated against BSRN station measurements for the entire globe (Pavlakis et al., 2004; Matsoukas et al., 2005).
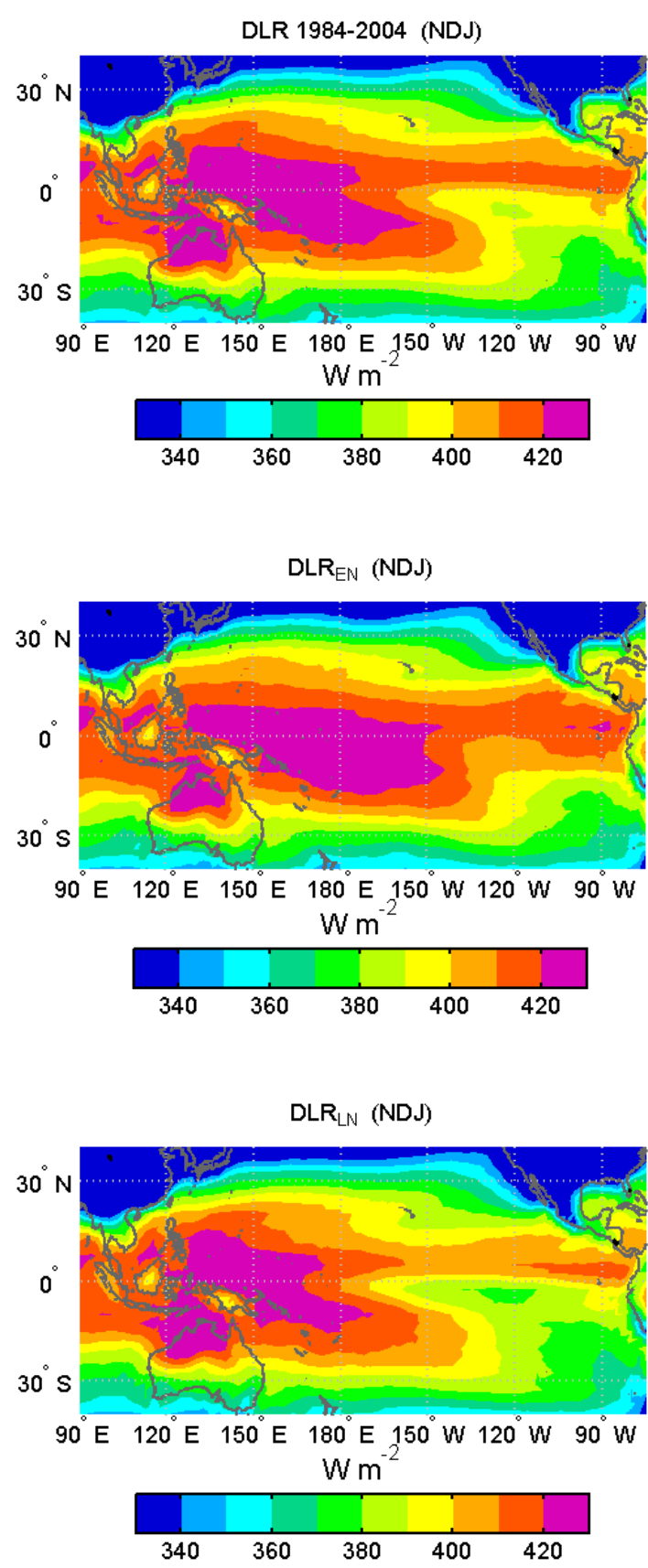

Fig. 1. The distribution of downward longwave radiation (DLR), over tropical and subtropical Pacific for the three month period November, December, January (NDJ); (a) long-term average (1984-2004), (b) average for five El Niño years, (c) average for five La Niña years.

\section{Long-term surface longwave radiation}

The geographical distribution of the 21-year average (19842004) DLR at the surface, over the tropical and subtropical Pacific Ocean $(40 \mathrm{~S}-40 \mathrm{~N}, 90 \mathrm{E}-75 \mathrm{~W})$, with a spatial 
Table 1. Definition of symbols used to represent radiation parameters.

\begin{tabular}{ll}
\hline Symbol & Definition \\
\hline DLR & Downward longwave radiation at surface \\
NSL & Net downwelling longwave radiation at the surface defined as DLR $-\varepsilon \sigma \mathrm{T}^{4}$ where \\
& the second term is the surface longwave emission \\
DLR $_{E N}, \mathrm{DLR}_{L N}, \mathrm{DLR}_{N E}$ & Mean DLR when El Niño, La Niña, or neutral conditions prevail, respectively \\
NSL $_{E N}, \mathrm{NSL}_{L N}, \mathrm{NSL}_{N E}$ & Mean NSL when El Niño, La Niña, or neutral conditions prevail, respectively \\
DLR-A $_{L N}$ & El Niño DLR anomaly with respect to the mean DLR for the La Niña years equal to \\
& DLR $_{E N}$-DLR \\
DLR-A & DLR anomaly with respect to all years DLR \\
\hline
\end{tabular}

resolution of $2.5^{\circ}$ (latitude) $\times 2.5^{\circ}$ (longitude), is shown in Fig. 1 top panel (a), for the 3-month period November, December and January (NDJ). The three month period NDJ is selected as best representing the mature phase of ENSO evolution, as the ENSO peak typically occurs late in the calendar year (December-January). It is within this period that the strongest changes in the DLR occur (see Sect. 4).

The five significant El Niño events in our 21-year study period, 1984-2004, were during 1986-1987, 1991-1992, 1994-1995, 1997-1998 and 2002-2003. In the same period, the more significant La Niña events were during 1984-1985, 1988-1989, 1998-1999, 1999-2000, 2000-2001 (Trenberth, 1997; Wang and Fiedler, 2006). We have calculated, for each grid-box, the mean monthly DLR averaged over the 11 neutral years $\left(\mathrm{DLR}_{N E}\right)$, i.e. the years when no significant El Niño or La Niña events occurred for the period NDJ. Both the long-term mean DLR and the DLR $\operatorname{DR}_{N E}$ for NDJ show similar spatial patterns and their values have differences less than $5 \mathrm{Wm}^{-2}$. Thus only the long-term mean DLR is shown, which is representative of normal conditions. As expected, the maxima in DLR, reaching about $430 \mathrm{Wm}^{-2}$, occur over the western Pacific, where the Western Pacific Warm Pool is located. The highest open ocean water temperatures on Earth are observed there. Because of these high temperatures, the atmosphere is supplied with large amounts of water vapour, the most important greenhouse gas, resulting in high DLR values.

We also computed, for each grid-box, the average DLR over the five years ${ }^{1}$ when El Niño $\left(\operatorname{DLR}_{E N}\right)$ conditions prevailed (Fig. 1, middle panel $b$ ) and the corresponding average DLR over the five years when La Niña $\left(D_{L R} R_{L N}\right)$ conditions prevailed (Fig. 1, bottom panel c), for the three month period of NDJ. It is evident from these figures that high values of DLR are observed over much more extended areas of the central and eastern Pacific, during the El Niño years compared to the La Niña average.

In Fig. 2, top panel (a) we show the geographical distribution of the 21-year average (1984-2004) net downwelling

\footnotetext{
${ }^{1} \mathrm{An}$ "El Niño year" is defined, for our purposes, as starting in July and ending in June of the next year.
}

longwave radiation at the surface (NSL) for the three-month period NDJ. The NSL is defined as NSL $=\mathrm{DLR}-\varepsilon \sigma \mathrm{T}^{4}$, where $\varepsilon \sigma \mathrm{T}^{4}$ is the surface longwave emission, $\varepsilon$ is the ocean surface emissivity taken to be 0.95 and $\mathrm{T}$ is the SST. The surface emissivity for non-oceanic areas was computed by using surface-type cover fractions from the ISCCP-D2 database and the land surface emissivity set to 0.9. We have also calculated, for each grid-box, the mean monthly NSL for NDJ averaged over the 11 neutral years $\left(\mathrm{NSL}_{N E}\right)$. The NSL and $\mathrm{NSL}_{N E}$ show similar values over the tropical and subtropical Pacific thus only the long-term NSL is presented in Fig. 2, which is representative of normal conditions. Clearly, NSL is negative over most of the region. The highest negative values, reaching $40-45 \mathrm{Wm}^{-2}$, occur in the central and southeastern Pacific.

In Fig. 2 are also shown the average NSL over the five years when El Niño ( $\mathrm{NSL}_{E N}$ ) conditions prevailed for NDJ (middle panel $b$ ), and the corresponding average NSL over the five years when La Niña $\left(\mathrm{NSL}_{L N}\right)$ conditions prevailed (bottom panel c). It is clear from these figures that when El Niño conditions prevail, the thermal radiative cooling in the central and south-eastern tropical Pacific becomes weaker.

During ENSO warm (El Niño) or cold (La Niña) phases, the equatorial Pacific warms or cools, respectively, by as much as $3^{\circ} \mathrm{C}$. This warming or cooling of the Pacific ocean is accompanied by significant changes in DLR and NSL, as shown in Figs. 1 and 2, indicating a significant change in the longwave radiation budget of the region.

In Fig. 3a we show the distribution of the difference $\mathrm{DLR}_{E N}-\mathrm{DLR}_{L N}$, over the tropical and subtropical Pacific. This difference will be referred to as the El Niño DLR anomaly $\left(\mathrm{DLR}-\mathrm{A}_{L N}\right)$ with respect to La Niña DLR. In the same figure, the rectangles designate the regions most commonly used to define El Niño indices, based on sea surface temperature, for monitoring and identifying El Niño and La Niña events (Hanley et al., 2003). The Niño-1+2 region, $(0-10 \mathrm{~S}, 80-90 \mathrm{~W})$ is the region that warms first in most El Niños, especially before 1976. For some time, the Niño-3 region $(5 \mathrm{~S}-5 \mathrm{~N}, 150-90 \mathrm{~W})$ was used for the monitoring of El Niño, but in recent years the Niño-3.4 region $(5 \mathrm{~S}-5 \mathrm{~N}$, 
170-120 W), somewhat further to the west of the Niño-3 region is used widely as a region with high SST anomalies and with a proximity with the main deep-convection centers during ENSO events. As can be seen in Fig. 3 a the DLR-A $A_{L N}$ obtains the highest values, reaching a maximum of about $+30 \mathrm{Wm}^{-2}$, in a broad swath in the Central Pacific extending to the coast of South America. This region almost coincides with Niño-3.4. In the western Pacific, on the other hand, the sign of the DLR-A $A_{L N}$ is reversed, with the DLR ${ }_{E N}$ being lower by $5-10 \mathrm{Wm}^{-2}$ than $\mathrm{DLR}_{L N}$.

In Fig. 3b we also show the corresponding El Niño NSL anomaly with respect to La Niña years $\left(\mathrm{NSL}_{-} \mathrm{A}_{L N}\right)$. It is evident, the NSL- $A_{L N}$ values are much lower than the DLR-A $\mathrm{A}_{L N}$ values, ranging between about $-10 \mathrm{Wm}^{-2}$ and $+15 \mathrm{Wm}^{-2}$. The highest values of NSL- $\mathrm{A}_{L N}$ appear south of Niño-3 and Niño-3.4 regions. Generally, a net thermal radiative heating of the central and eastern Pacific occurs during El Niño with respect to the La Niña years, and a net cooling of the western Pacific, that includes Indonesia and Northern Australia.

\section{DLR variation during ENSO evolution}

In this section, we investigate the evolution of ENSO related changes in the distribution and values of DLR over the tropical and subtropical Pacific.

First, we investigate the evolution of each El Niño or La Niña event, in the representative Niño-3.4 region, in order to define the time-span of the early, mature and decay phases of the phenomenon with respect to DLR. We thus calculate the mean monthly DLR in the Niño-3.4 region averaged over the 11 neutral years $\left(\mathrm{DLR}_{N E}^{[3.4]}\right)$, i.e. the years when no significant El Niño or La Niña events occurred. We then defined the parameter $\Delta(\mathrm{DLR})_{3.4}=D L R_{E N}^{[3.4]}-\mathrm{DLR}_{N E}^{[3.4]}$, which gives the difference between the mean monthly DLR in the Niño3.4 region $\left(\operatorname{DLR}_{E N}^{[3.4]}\right)$ for each El Niño event and the average neutral year DLR (DLR ${ }_{N E}^{[3.4]}$ ) for the same month.

In Fig. 4 a, we show the time evolution of $\Delta(\text { DLR })_{3.4}$ for each El Niño event. The same procedure is followed for the La Niña events, and the corresponding plots for the individual La Niñas are shown in Fig. 4b. In order to facilitate the interpretation of these figures and to show clearly the beginning and end of an event, we present 24-month time-series.

It is evident from Fig. 4 that the maximum DLR change during warm (El Niño) or cold (La Niña) ENSO events occurs between November and January, except for the 19861987 El Niño, which displays a double peak behaviour (see also Wang and Fiedler, 2006), with a second maximum around August 1987. Usually the highest value of $\Delta(\mathrm{DLR})_{3.4}$ occurs within the 3-month period from November to January. Consequently, in our subsequent analysis we use the three month period of November, December and January (NDJ) to study the mature phase of El Niño or La Niña events, August, September and October (ASO) for the earlier

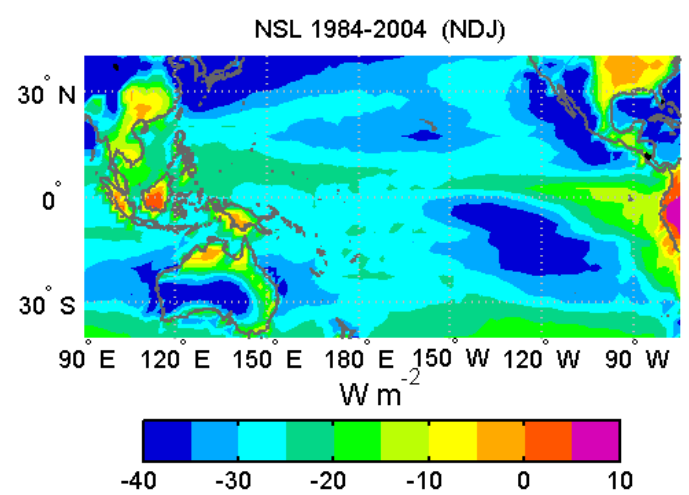

(a)
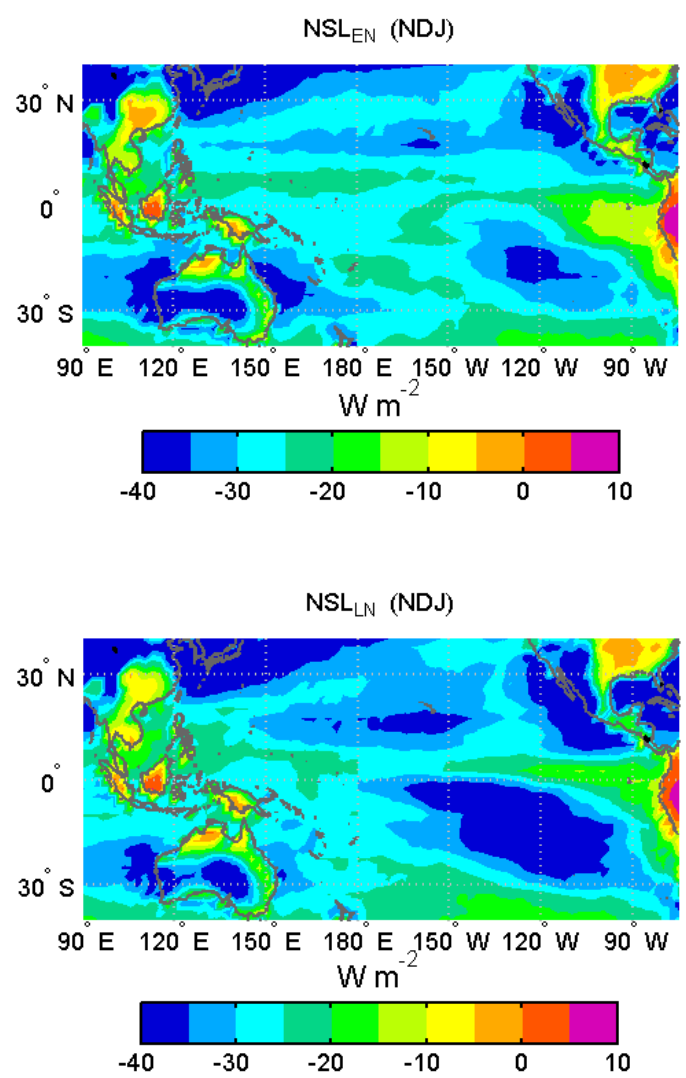

(c)

Fig. 2. The distribution of net surface longwave radiation (NSL), over tropical and subtropical Pacific for the three month period November, December, January (NDJ); (a) long-term average (1984-2004), (b) average for five El Niño years, (c) average for five La Niña years.

stages of ENSO development and February, March and April (FMA) for the decay phase of ENSO. Thus, in spite of the significant differences in the onset and evolution of individual ENSO events, the ASO, NDJ, and FMA periods provide a frame of reference for studying in broad terms the evolution of ENSO. 

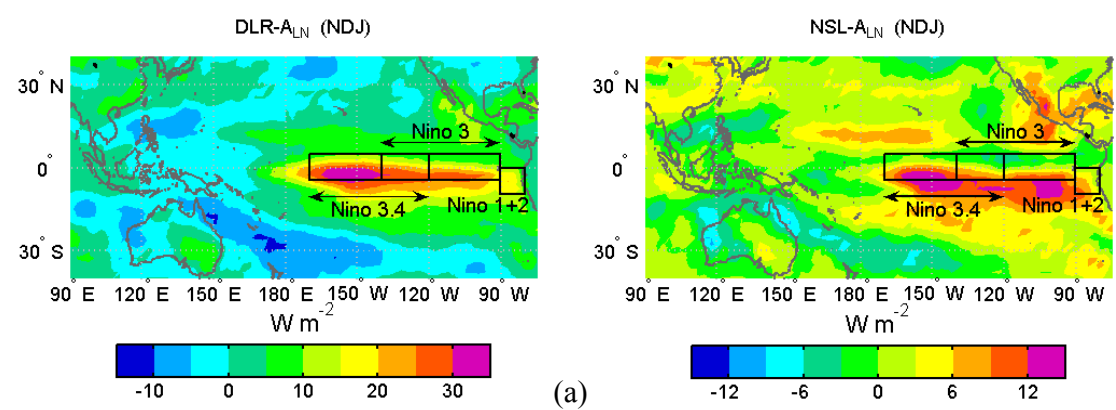

(b)

Fig. 3. (a): Differences in the mean downward longwave radiation (DLR), between the El Niño and La Niña years, over tropical and subtropical Pacific for the period of November, December and January (NDJ), (b): The same but for NSL.

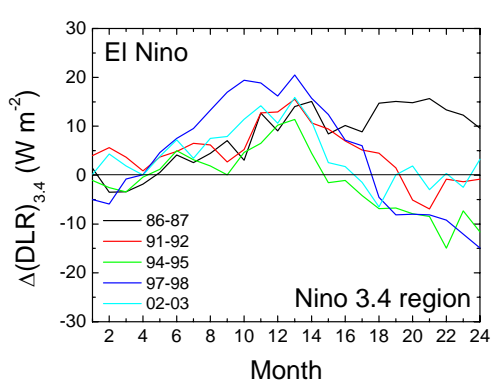

(a)

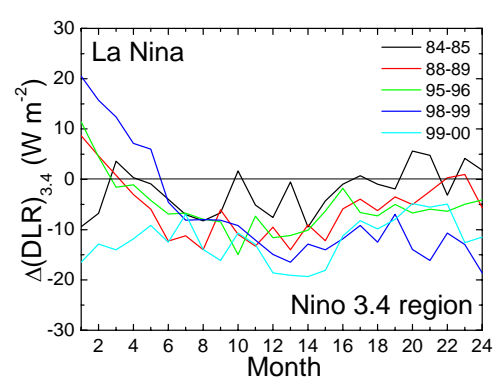

(b)

Fig. 4. DLR differences between the warm ENSO phase and neutral years; (a) in the Niño-3.4 region (5 S-5 N, 170-120 W) from January of each ENSO development to December of the following year, (b) the same but for the cold ENSO phase.

\subsection{El Niño events}

We now define the difference $\operatorname{DLR}_{E N}-\mathrm{DLR}$, as the El Niño DLR anomaly with respect to the long-term average (El Niño DLR-A). This quantity gives the change in DLR during El Niño years with respect to normal condition. In Fig. 5 (left side) we show the distribution of El Niño DLR-A for the three month periods of ASO (top panel), NDJ (middle panel) and FMA (bottom panel), at $2.5 \times 2.5$ spatial resolution.

The DLR-A during the early stage of El Niño development is around $+10 \mathrm{Wm}^{-2}$ in the equatorial central Pacific and $10 \mathrm{Wm}^{-2}$ in the western Pacific over Indonesia and Northern Australia. During the mature phase of El Niño, high values of DLR-A are observed in a region confined around the equator, between $10 \mathrm{~S}-5 \mathrm{~N}$ that extents from the central Pacific (near the date line) to the coast of Peru. The values of the DLRA reach about $+20 \mathrm{Wm}^{-2}$ over most of the Niño-3.4 region. During the decay phase of El Niño, values of DLR-A up to $+10 \mathrm{Wm}^{-2}$ are observed roughly in the same equatorial central Pacific region as during the mature ENSO phase, but in the eastern Pacific this region now shifts north of the equator up to the south coast of Mexico (15 N). In the western Pacific DLR-A values of opposite sign are observed with values up to $-10 \mathrm{Wm}^{-2}$ over the South China Sea.
In order to investigate and identify the regions that show significant changes in the DLR during El Niño years with respect to the long-term values, we performed for each gridbox and for each 3-month period (ASO, NDJ, FMA) a twotailed Student's t-test. Our two samples are the 3-monthly DLR values for the period 1984-2004 and the corresponding values for the 5 years when El Niño conditions prevailed. The null hypothesis is that the mean values of the two samples are equal and the alternative hypothesis is that these values are different. On the right-hand side of Fig. 5 we show the geographical distribution of the P-values for the ASO (top panel), NDJ (middle panel) and FMA (bottom panel). Grid-boxes with P-values smaller than 0.05 are considered to have statistically significant El Niño DLR-A values. During the mature phase of ENSO, the statistical significance of the anomalies is very high over the Niño-3.4 (the smallest $\mathrm{P}$-value is 0.004 , observed in this region) and Niño- $1+2$ regions (P-values less than 0.02 ) as well as the region between them. P-values less than 0.01 are observed over two regions: a sub-region of Niño-3.4, i.e. $5 \mathrm{~N}-5 \mathrm{~S}, 160-130 \mathrm{~W}$ and a second region in the eastern Pacific between $0-5 \mathrm{~S}$ and $115-90 \mathrm{~W}$. There is no significant DLR signal in the western Pacific during the mature phase of ENSO. On the other hand, during the early phase (ASO), the anomalies appear to 

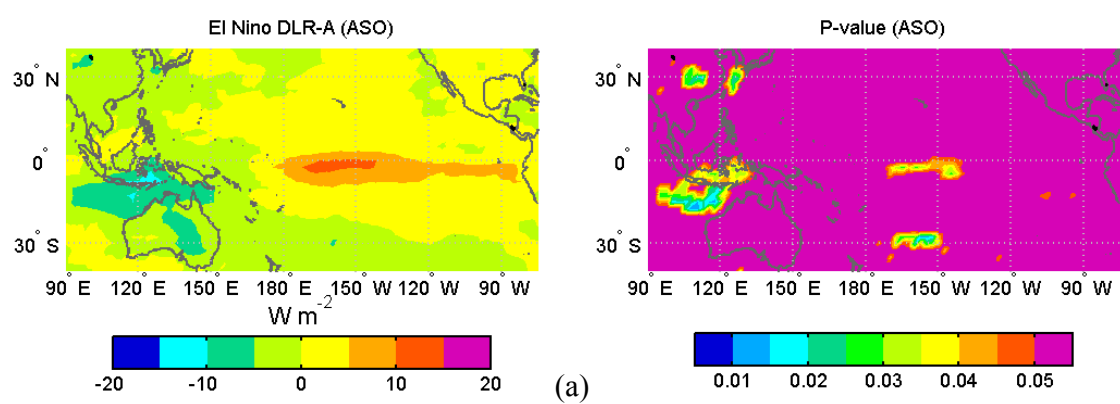

(b)
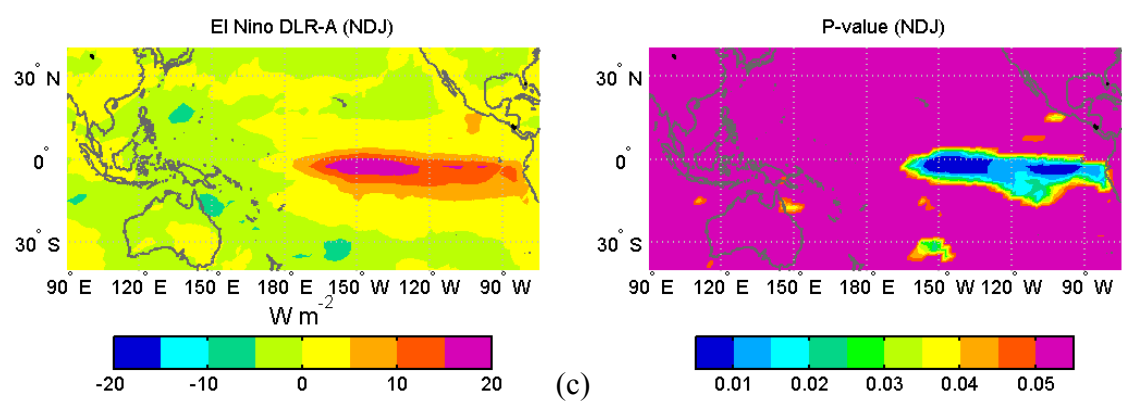

(c)

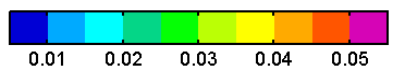

(d)
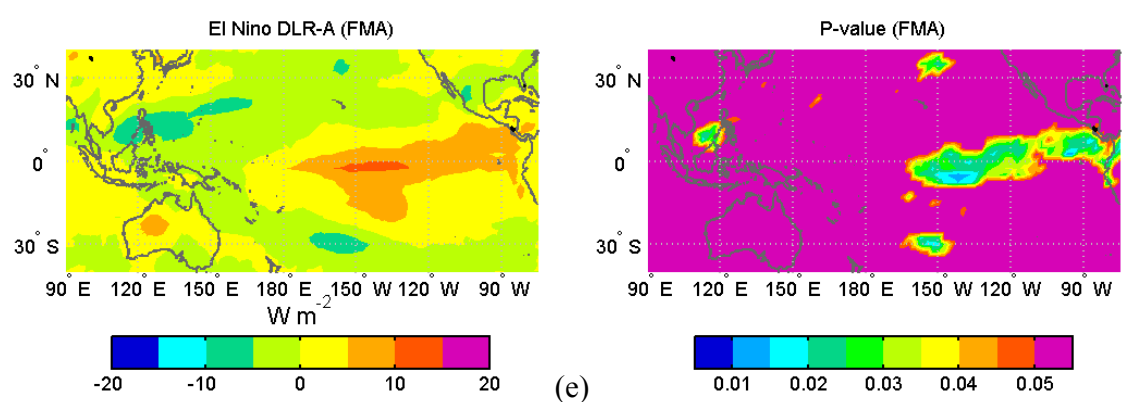

(f)

Fig. 5. Left: The distribution at $2.5 \times 2.5$ spatial resolution of El Niño DLR-A for ASO (top panel), NDJ (middle panel), and FMA (bottom panel). Right: The distribution of P-values from a Student's t-test.

be significant over a region in the western Pacific, over Indonesia (smallest P-value of about 0.02). The DLR change in this region precedes the appearance of significant high values of DLR anomalies in the Niño-3.4 region. This will be further discussed in Sect. 6. During the decay ENSO phase P-values less than 0.02 are observed over two regions: a region in the central Pacific 10-0 S, 130-150 W and a region in eastern Pacific 0-10 N, 80-100 W. Further, P-values around 0.03 are found over the South China Sea.

A similar analysis was conducted for the El Niño NSL anomalies (not shown here). The various parameters are defined in the same way as above but for NSL. The El Niño NSL-A during the early stages (ASO period) of El Niño development has a minimum value of about $-10 \mathrm{Wm}^{-2}$ over central and eastern Indonesia with P-value less than 0.03. In contrast, over the central Pacific the signal is not significant. During the mature phase of El Niño (NDJ), the NSL-A is around $+10 \mathrm{Wm}^{-2}$ south of the equator in the central Pacific (10-0 S, 160-120 W) with P-values less than 0.02. During the decay phase (FMA) there is a NSL-A of about $-10 \mathrm{Wm}^{-2}$ over the South China Sea with P-values of about 0.02 .

\subsection{La Niña events}

A similar analysis was conducted for the DLR anomalies during La Niña events. The various parameters are defined in the same way as in Sect. 4.1, but for the La Niña years. Instead of the suffix EN (El Niño), we use here the suffix LN (La Niña). The resulting geographical distribution of the La Niña DLR anomalies (DLR-A), with respect to the long-term average, is shown on the left in Fig. 6 at the top panel for ASO, the middle panel for NDJ and the bottom panel for FMA. Large negative values (i.e. lower DLR for the La Niña years) of about $-20 \mathrm{Wm}^{-2}$ are observed in the central equatorial Pacific, in the region $2.5 \mathrm{~S}-2.5 \mathrm{~N}, 170-150 \mathrm{~W}$ during the mature ENSO 

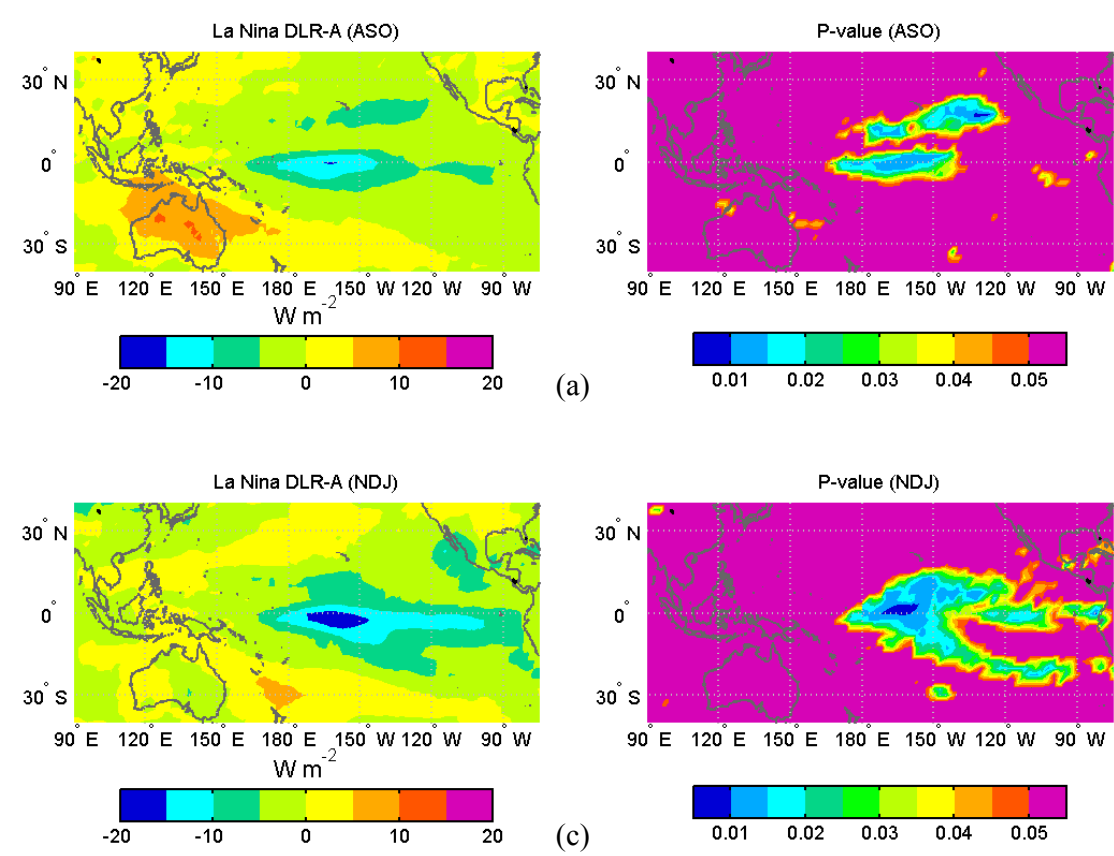

(b)
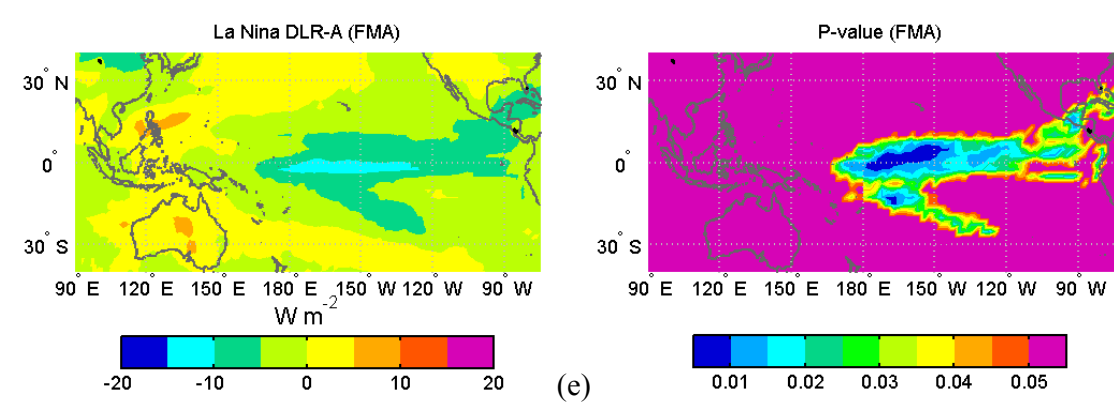

(d)

Fig. 6. Left: The distribution at $2.5 \times 2.5$ spatial resolution of La Niña DLR-A for ASO (top panel), NDJ (middle panel), and FMA (bottom panel). Right: The distribution of P-values from a Student's t-test.

phase (i.e. during NDJ). In the same region values of DLR-A of about $-10 \mathrm{Wm}^{-2}$ are observed during both the early and decay phases of La Niña.

On the right side of Fig. 6 we present the geographical distribution of P-values, which confirms that the region in the Central Pacific indicated above, displays statistically significant anomalies during all three, phases (i.e. ASO, NDJ, FMA) of La Niña with P-values less than 0.02.

\section{Correlation of Niño-3.4 index and DLR anomaly}

The Niño-3.4 index based on sea surface temperature (SST) is used extensively in recent years for identifying El Niño or La Niña events. The strength of the events is quantified as the three-month smoothed SST departures from normal SST, in the Niño-3.4 region in the equatorial Pacific. For the same region (Niño-3.4), we have calculated the 3-month smoothed anomaly of the mean monthly DLR at the surface with respect to the average monthly DLR for the whole study period 1984-2004. This parameter will be denoted by DLRA[3.4] and will be called "DLR-A[3.4] index".

Figure 7a shows the time-series of the DLR-A[3.4] index for the period 1984-2004 (black line). For comparison we have overlaid on the same diagram the time-series of the Niño-3.4 SST index (red line). The agreement between the two time-series is excellent. In both time-series there are clear peaks during El Niño events and minima for the La Niña events. Moreover, the relative strengths of warm and cold ENSO events are very similar. DLR-A[3.4] reaches values as high as $+20 \mathrm{Wm}^{-2}$ (during the strong 1997-1998 El Niño), and as low as $-20 \mathrm{Wm}^{-2}$ (during the La Niña of 2000-2001).

Figure $7 \mathrm{~b}$ shows the corresponding time-series of the 3-month smoothed anomaly (NSL-A[3.4]) of the mean monthly NSL with respect to the average monthly NSL for the whole study period 1984-2004 in the Niño-3.4 region. 


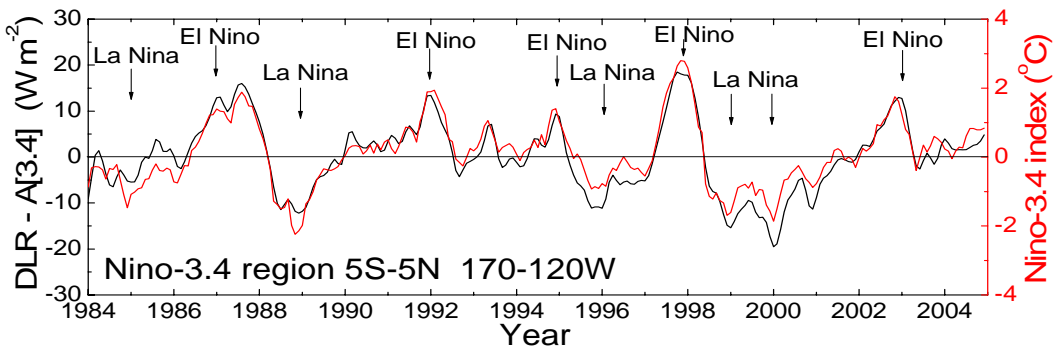

(a)

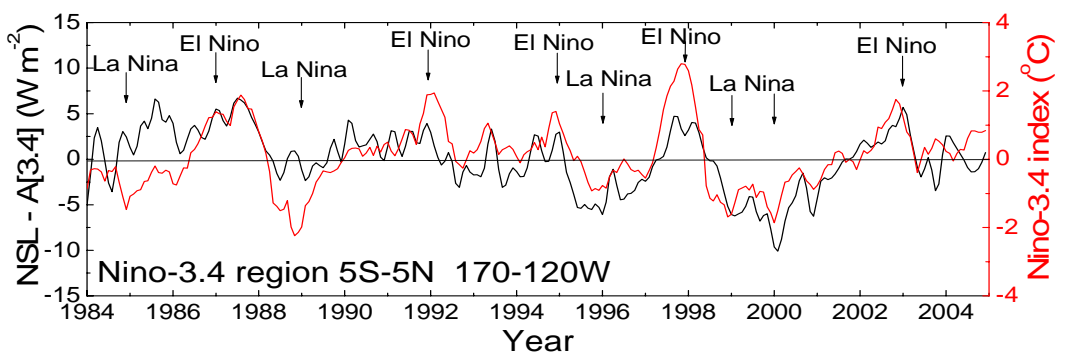

(b)

Fig. 7. Time-series of downward longwave radiation (DLR-A[3.4]), and net downwelling longwave radiation at the surface (NSL-A[3.4]) anomaly (defined with respect to the average monthly DLR for the whole study period 1984-2004) in the Niño-3.4 region (black line). Overlaid is the time-series of the Niño-3.4 index (red line).

The NSL-A[3.4] shows lower variability than the DLR$\mathrm{A}[3.4]$ but this is at least partly due to the fact that the region of the most significant NSL changes during the ENSO lies to the south of the Niño-3.4 region (see Fig. 3b).

Linear regression between DLR-A[3.4] and the Niño-3.4 index yielded a correlation coefficient of $\mathrm{r}=0.91$ and a slope of $7.7 \pm 0.2 \mathrm{Wm}^{-2} /{ }^{\circ} \mathrm{C}$, as shown in Fig. 8a. The corresponding plot for NSL-A[3.4] vs. the Niño-3.4 index is shown in Fig. 8b. The correlation coefficient is 0.51 and the slope equals $2.0 \pm 0.2 \mathrm{Wm}^{-2} /{ }^{\circ} \mathrm{C}$. These values show that during $\mathrm{El}$ Niño conditions in the Niño-3.4 region, the DLR increases at a higher rate than the longwave emission from the surface due to the increase in the sea surface temperature. Thus the NSL in the Niño-3.4 region increases during the warm phase of ENSO by roughly $2 \mathrm{Wm}^{-2}$ for a 1 degree increase in SST. This is consistent with the term "super greenhouse effect" (Ramanathan and Collins 1991; Inamdar and Ramanathan 1994) whereby the trapping of longwave radiation in the atmosphere increases faster than the longwave emission from the Earth's surface as the temperature increases.

In Fig. 9a we show the geographical distribution of the correlation coefficient given by linear regression of the timeseries of DLR-A in each $2.5 \times 2.5$ degree grid-box and the Niño-3.4 index time-series. The maximum values of the correlation coefficient are observed, expectedly, in the Niño-3.4 region itself although there are values higher than 0.5 all over the central and eastern Pacific. In the western Pacific there is an anti-correlation between the DLR-A and Niño-3.4 index time-series, although in absolute terms the correlation coefficients are not as high as in the eastern Pacific.

In Fig. 9b, we also show the distribution of the correlation coefficient given by linear regression of the time-series of NSL-A in each $2.5 \times 2.5$ degree grid-box and the Niño-3.4 index time-series. The maximum values of the correlation coefficient here do not exceed 0.7 and they are observed over a smaller region, to the south of the Niño-3.4 region, at (0$10 \mathrm{~S}, 160-140 \mathrm{~W})$.

\section{Time lag between western and eastern Pacific DLR Anomalies}

There is a region in the western Pacific (central Indonesia) which displays significant anomalies during the early phase (ASO) of ENSO development. The DLR anomalies in this region seem to precede the appearance of significant anomalies in the Niño-3.4 region. In order to further investigate this, we have produced correlation coefficients for each $2.5 \times 2.5$ grid-box, between the time-series of the DLR-A in each pixel and the time-series of the DLR-A[3.4] index, after introducing in the latter a time shift of $-1,-2, \ldots,-8$ months. We constructed geographical distributions of the correlation coefficients, and compared them against the map with zero time lag (Fig. 9a). In all cases but one, the correlation 


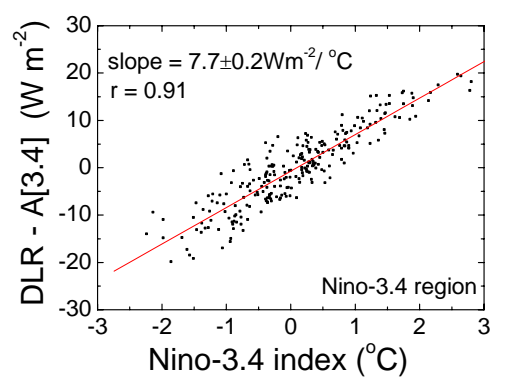

(a)

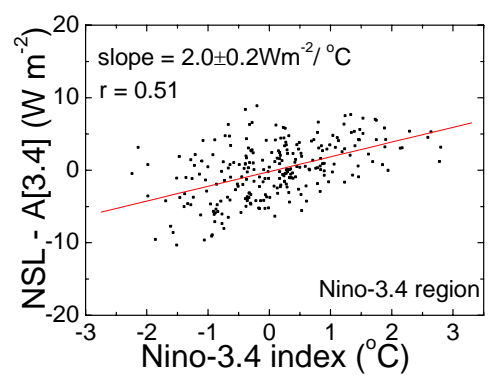

(b)

Fig. 8. (a) Scatter plot between the DLR-A[3.4] and the Niño-3.4 index, (b) between the NSL-A[3.4] and the Niño-3.4 index.

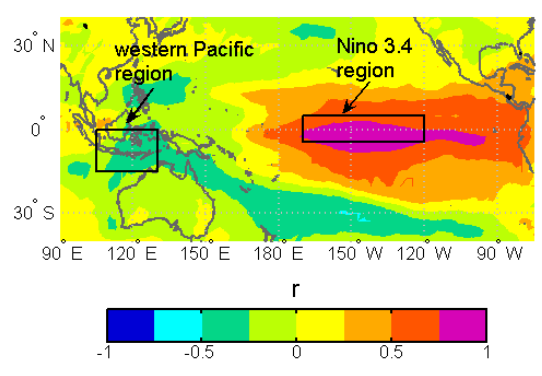

(a)

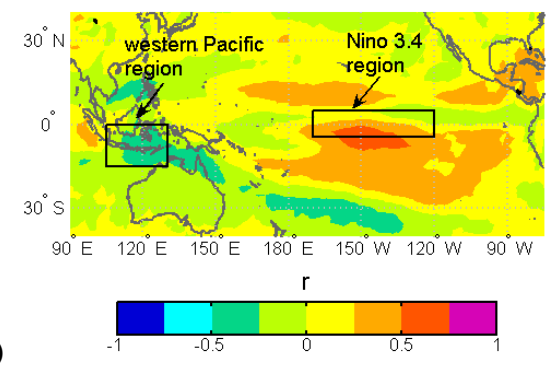

(b)

Fig. 9. Geographical distribution of correlation coefficient between, (a) DLR-A and the Niño-3.4 index, (b) NSL-A and Niño-3.4 index.

deteriorated over the entire area. The one exception is shown in the map of the 3-month shift (Fig. 10a). There is a region in the western Pacific, north of Australia (central Indonesia), indicated by a rectangle (0-15 S, 105-130E), where the (anti)correlation improves, and takes its highest absolute value when the time-series of the DLR-A[3.4] index is shifted by -3 months. The maximum value of the correlation coefficient increases in absolute value from 0.42 with no time shift, to 0.57 with a 3 -month time shift.

We have, subsequently, calculated the correlation coefficient between the average DLR-A in the western Pacific rectangle shown in Fig. 10a and the DLR-A[3.4] index shifted by $0,-1, . .,-8$ months. In Fig. 10b we have plotted the value of this correlation coefficient (the values are negative, because the two DLR anomalies are anti-correlated) as a function of the time lag introduced (in months). It is again obvious that highest anti-correlation is observed when the DLR-A[3.4] index time-series is shifted by -3 to -4 months. This means that DLR anomalies in the western Pacific rectangle precede the anomalies in the Niño-3.4 region by 3-4 months. The significance of the western Pacific for initializing El Niño has already been noted by Wang (2002) who found that the 850-mb zonal wind anomalies in the western Pacific region with coordinates $5 \mathrm{~S}-5 \mathrm{~N}, 120-170 \mathrm{E}$ lead the Niño-3 SST anomalies by 4 months (note the overlap of our western Pacific region with that of Wang 2002).
In Fig. 11a, we show the mean DLR-A time-series in the western Pacific rectangle (black line). For comparison we have overlaid on the same diagram the DLR-A[3.4] index time-series (red line). It is clear that the DLR-A in the western Pacific shows a minimum before the peak of the DLR$\mathrm{A}$ [3.4] index for each El Niño. The minimum value of the DLR-A in the western Pacific is about $-15 \mathrm{Wm}^{-2}$ before the intense 1997-1998 El Niño.

In Fig. 11b, we also show the mean NSL-A time-series in our western Pacific rectangle (black line) and the DLRA[3.4] index time-series (red line). The behaviour of the NSL-A time-series in the western Pacific rectangle is very similar to that of DLR-A, although the variability is much lower.

\section{Effects of total precipitable water and cloud amount variability on DLR during ENSO}

The air temperature and the water vapour content of the atmosphere, especially of the lower atmospheric layer, play the most important role in determining the DLR reaching the Earth's surface, followed in order of significance by the cloud amount of low, middle and high cloud, respectively (Pavlakis et al., 2004).

The time-series of the anomaly of the mean monthly DLR in the Niño-3.4 region (DLR-A [3.4] index) with respect to the average monthly DLR for the entire study period 

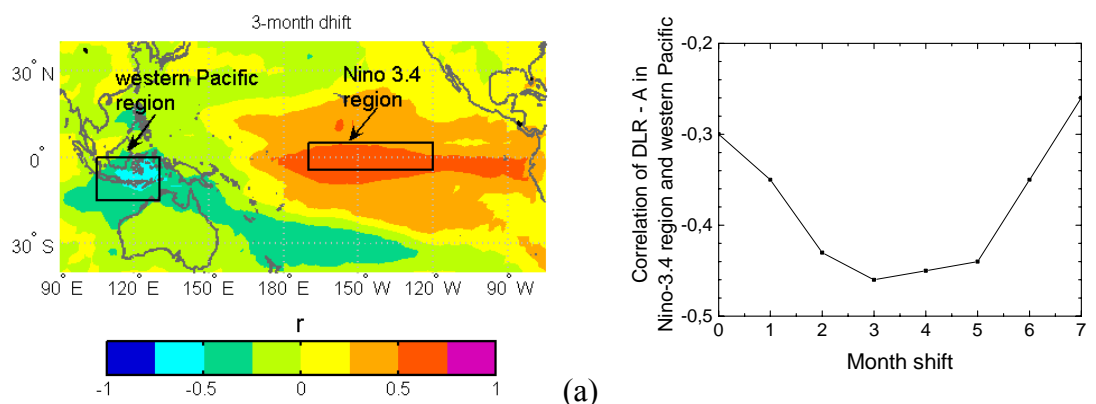

(a)

(b)

Fig. 10. (a) Geographical distribution of correlation between the DLR-A and the DLR-A[3.4] in the Niño-3.4 region with a 3-month shift, (b) correlation coefficient of the DLR-A in the western Pacific and the DLR-A[3.4] as a function of the number of months shift of the DLR-A[3.4].

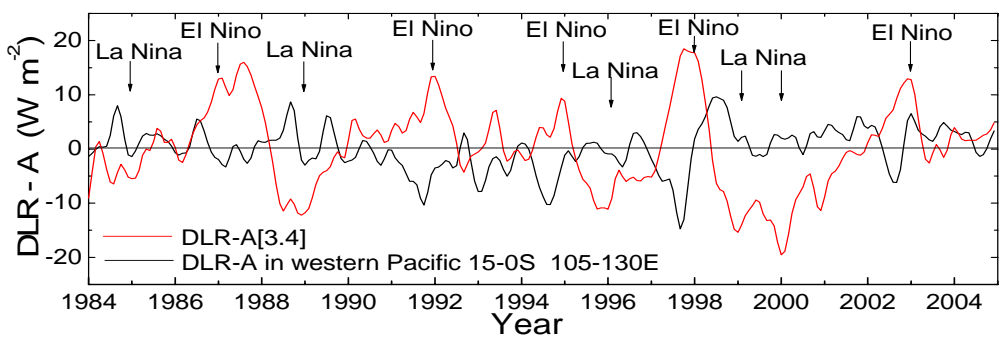

(a)

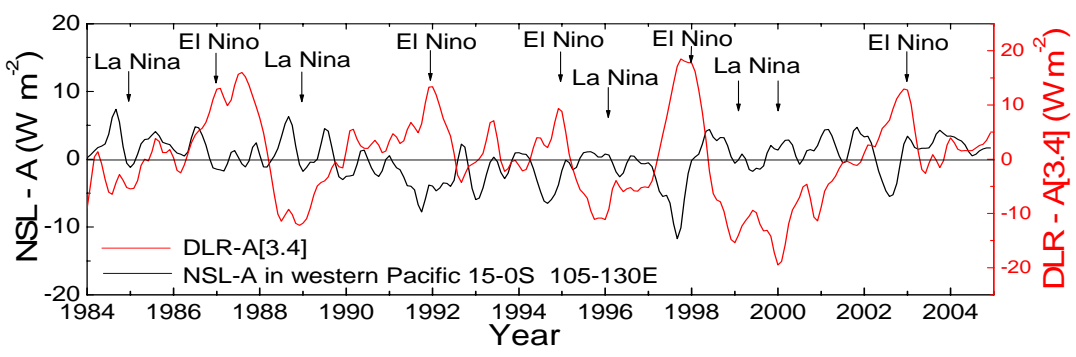

(b)

Fig. 11. Downward longwave radiation (DLR), and net downwelling longwave radiation at the surface (NSL) anomaly time series in the western Pacific region 15 S-15 N, 120-140 E (black line) compared with DLR anomaly in Niño-3.4 region (red line).

1984-2004, shows an excellent correlation with the Niño3.4 index. This is due to the fact that the Niño-3.4 index is based on sea surface temperature (SST) which is linked to the water vapour content of the atmosphere. We calculated the anomaly of the mean monthly total column water vapour with respect to the average monthly total column water vapour from the NCEP/NCAR database for the whole study period 1984-2004 in the Niño-3.4 region (Total water-A[3.4]). Linear regression between the Total water$\mathrm{A}[3.4]$ and the Niño-3.4 index yielded a correlation coefficient of 0.84 and a slope of $0.31 \pm 0.01 \mathrm{~g} \mathrm{~cm}^{-2} /{ }^{\circ} \mathrm{C}$, as shown in Fig. 12a.
We also calculated the anomaly of the mean monthly low, middle and high-level cloud amount with respect to the corresponding values, for the whole study period 1984-2004 in the Niño-3.4 region. We then created scatter plots between these anomalies and the Niño-3.4 index. We found no correlation between the low cloud amount anomaly and the Niño3.4 index (correlation coefficient $r=0.1$ ). We note that there are uncertainties in ISCCP low cloud amount because from the satellite point of view low clouds under optically thick middle or high level clouds are not observed. Linear regression between the middle and high cloud amount anomalies and the Niño-3.4 index yielded a correlation coefficient of 


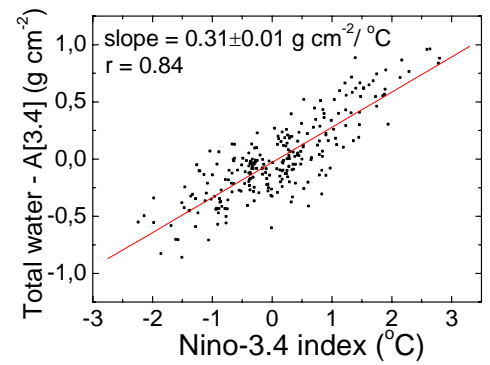

(a)

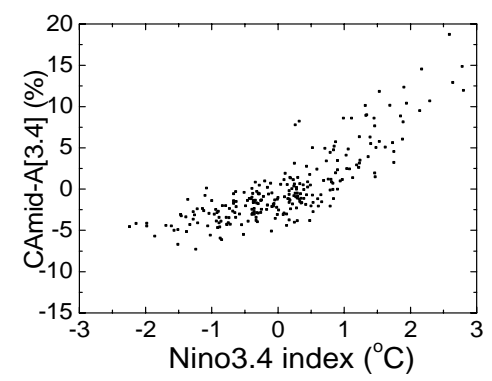

(b)

Fig. 12. (a) Scatter plot between the total column water vapour anomaly in the Niño-3.4 region and the Niño-3.4 index, (b) scatter plot between the middle cloud amount anomaly in the Niño-3.4 region and the Niño-3.4 index.

0.83 and 0.77 , respectively. In Fig. $12 \mathrm{~b}$ we show, as an example, the scatter plot of the middle cloud amount anomaly $\left(\mathrm{CA}_{\text {mid }}-\mathrm{A}[3.4]\right)$ versus the Niño-3.4 index. However, in the tropics the middle and high clouds only marginally influence the DLR owing to the high moisture in the lower part of the atmosphere (Tian and Ramanathan, 2002). This is verified by inspection of the scatter plot between $\mathrm{CA}_{\text {mid }}-$ A[3.4] and Niño-3.4 index (Fig. 12b). The slope in the scatter plot becomes steeper for values of Niño-3.4 index greater than $1.5^{\circ} \mathrm{C}$. The same is true for the scatter plot between high cloud amount anomaly and Niño-3.4 index (not shown here). The steeper slope in these scatter plots is indicative of the onset of deep convection in the region (Ramanathan and Collins 1991). The onset of deep convection however does not change the rate of increase of the DLR-A[3.4] for SST anomalies greater than $1.5^{\circ} \mathrm{C}$ (Fig. 8). In contrast other radiation variables crucial for the development of an ENSO event such as the downward shortwave radiation (DSR) at the surface or the longwave radiation absorbed by the atmosphere in the Niño-3.4 region are affected by the onset of deep convection.

The time-series of the mean monthly DLR anomaly (DLRA) in the region north of Australia (15 S-0 S, 105 E-130 E), exhibits an anti-correlation with the DLR-A [3.4] time-series and precedes it by 3-4 months. We have found that only the time-series of total water vapour anomaly (Total water-A) leads the DLR-A [3.4] time-series by 3-4 months in contrast with the time-series of the other parameters that influence the DLR. Linear regression between the Total water-A and the DLR-A [3.4] index yielded a correlation coefficient of -0.52 (anticorrelation). When the DLR-A[3.4] index was shifted by -3 months the highest anti-correlation is observed, with a value of -0.64 . The reduction of atmospheric water vapour in the western Pacific over the region of central Indonesia is in agreement with the reduction of precipitation over the same region that preceded the 1997/1998 El Niño, as observed by Curtis et al. (2001). We found no correlation between the low-level cloud amount anomaly and the DLR-A[3.4] index but this may be due to uncertainties in the ISCCP data.

\section{Conclusions}

To summarize, our model calculations, which are based on ISCCP-D2 cloud climatologies, and temperature and humidity profile information from NCEP/NCAR reanalysis, show a high variability in the downward longwave radiation (DLR) at the surface of the Earth and the net downwelling longwave radiation at the surface (NSL) over the tropical and subtropical Pacific Ocean during ENSO events. We have found that the enhancement of DLR during warm ENSO phases, compared with neutral years, is not confined to the Niño-3.4 region but extents over a much broader area in the central and eastern Pacific. This enhancement of DLR (DLR-A), for the three month period NDJ, is more than $+10 \mathrm{Wm}^{-2}$, in a broad swath in the central Pacific extending to the coast of South America. A maximum DLR-A, of about $20 \mathrm{Wm}^{-2}$, is observed within the Niño-3.4 region.

During the cold phases of ENSO, values of DLR-A less than $-10 \mathrm{Wm}^{-2}$ are observed in a small sub-region of the Niño-3.4 region $(2.5 \mathrm{~S}-2.5 \mathrm{~N}, 170-150 \mathrm{~W})$, for both ASO and FMA periods. Minimum values of DLR-A, of about $20 \mathrm{Wm}^{-2}$, are observed in the central Pacific near the dateline and within the Niño-3.4 region for the NDJ period, but in a more confined region compared with the corresponding values during the ENSO warm phases.

The absolute value of NSL shows less variability compared with DLR. The highest values of the enhancement of NSL during warm ENSO phases compared with cold ENSO phases, appear south of the Niño-3 and Niño-3.4 regions and are about $15 \mathrm{Wm}^{-2}$.

The Niño-3.4 index is very often used to define the phase and strength of ENSO events. We calculated the correlation coefficient given by linear regression of the time-series of the monthly DLR anomaly, referenced to the whole study period 1984-2004, in each $2.5 \times 2.5$ degree grid-box and the Niño-3.4 index, and found values higher than 0.5 over the central and eastern tropical Pacific. Values higher than 0.85 are observed in the Niño-3.4 region. Thus, the average DLR anomaly in the Niño-3.4 region (DLR-A [3.4] index), is a very useful index to describe and study ENSO events and 
can be used to asses whether or not El Niño or La Niña conditions prevail. It is important to note that DLR is an easily measurable quantity using a pyrgeometer and contains information both for oceanic (i.e. SST) and atmospheric (i.e. water vapour) processes.

We further investigated the DLR anomaly time-series in the western Pacific using the DLR-A [3.4] index time-series as our reference. We found a significant anti-correlation between the two time-series over the ocean north of Australia up to the equator. There is a region in the western Pacific over Indonesia and western Java (15-0 S, 105-130 E) where the DLR anomaly leads the corresponding anomaly in the Niño-3.4 region by 3-4 months. Thus, DLR measurements in this region will be very useful for the study of the time evolution of El Niño events.

Acknowledgements. The ISCCP-D2 data were obtained from the NASA Langley Research Center (LaRC) Atmospheric Sciences Data Center (ASDC). The NCEP/NCAR Global Reanalysis Project data were obtained from the National Oceanic and Atmospheric Administration (NOAA) Cooperative Institute for Research in Environmental Sciences (CIRES) Climate Diagnostics Center, Boulder, Colorado, USA.

Edited by: W. Conant

\section{References}

Bjerknes, J.: A possible response of the atmospheric Hadley circulation to equatorial anomalies of ocean temperature, Tellus, 18, 820-829, 1966.

Bjerknes, J.: Atmospheric teleconnections from the equatorial Pacific, Mon. Wea. Rev., 97, 163-172, 1969.

Cane, M. A., Matthias, M., and Zebiak, S. E.: A study of self excited oscillations of the tropical ocean-atmosphere system. Part I: Linear analysis, J. Atmos. Sci., 47, 1562-1577, 1990.

Chou, Shu-Hsien, Chou, Ming-Dah, Chan, Pui-King, Lin, PoHsiung, and Wang, Kung-Hwa: Tropical warm pool surface heat budgets and temperature: Contrasts between 1997/98 El Niño and 1998/99 La Niña, J. Climate, 17, 1845-1858, 2004.

Curtis, S. and Adler, R.: ENSO indices Based on patterns of satellite-derived precipitation, J. Climate, 13, 278-2793, 2000.

Curtis, S., Adler, R., Huffman, G., Nelkin, E., and Bolvin, D.: Evolution of tropical and extratropical precipitation anomalies during the 1997-1999 ENSO cycle, Int. J. Climatol., 21, 961-971, 2001.

Dijkstra, H. A.: The ENSO phenomenon: theory and mechanisms, Adv. Geosci., 6, 3-15, 2006,

http://www.adv-geosci.net/6/3/2006/.

Fedorov, A. V., Harper, S. L., Philander, S. G., Winter, B., and Wittenberg, A.: How predictable is El Niño?, BAMS 84, 911-919, 2003.

Hanley, D. E., Bourassa, M. A., O’Brien, J. J., Smith, S. R., and Spade, E. R.: A quantitative evaluation of ENSO Indices, J. Climate, 16, 1249-1258, 2003.

Harrison, M. J., Rosati, A., Soden, B. J., Galanti, E., and Tziperman, E.: An evaluation of Air-Sea flux products for ENSO simulation and prediction, Mon. Wea. Rev., 130, 723-732, 2002.
Hatzianastassiou, N., Croke, B., Kortsalioudakis, N., Vardavas, I., and Koutoulaki, K.: A model for the longwave radiation budget of the NH: Comparison with Earth Radiation Budget Experiment data, J. Geophys. Res., 104, 9489-9500, 1999.

Hatzianastassiou, N. and Vardavas, I.: Shortwave radiation budget of the Southern Hemisphere using ISCCP C2 and NCEP/NCAR climatological data, J. Climate, 14, 4319-4329, 2001.

Inamdar, A. K. and Ramanathan V.: Physics of greenhouse effect and convection in warm oceans, J. Climate, 7, 715-731, 1994.

IPCC, 2001: Climate Change: The Scientific Basis. Contribution of Working Group I to the Third Assessment Report of the Intergovernmental Panel on Climate Change, edited by: Houghton, J. T., Ding, Y., Griggs, D. J., Noguer, M., van der Linden, P. J., Dai, X., Maskell, K., and Johnson, C. A., Cambridge University Press, Cambridge, United Kingdom and New York, NY, USA, 2001.

Jin, F. F.: An equatorial ocean recharge paradigm for ENSO. Part I: Conceptual model, J. Atmos. Sci., 54, 811-829, 1997a.

Jin, F. F.: An equatorial ocean recharge paradigm for ENSO. Part II: A stripped-down coupled model, J. Atmos. Sci., 54, 830-847, $1997 b$.

Kistler, R., Kalnay, E., Collins, W., Saha, S., White, G., Woollen J., Chelliah, M., Ebisuzaki, W., Kanamitsu, M., Kousky, V., van den Dool, H., Jenne, R., and Fiorino, M.: The NCEP-NCAR 50-Year Reanalysis: Monthly Means CD ROM and Documentation, Bull. Am. Meteorol. Soc., 82, 247-268, 2001.

McCreary, J. P. and Anderson, D. L. T.: An overview of coupled ocean-atmosphere models of El Niño and the Southern Oscillation, J. Geophys. Res., 96, 3125-3150, 1991.

McPhaden, M. J., Busalacchi, A. J., Cheney, R., et al.: The tropical ocean-global atmosphere observing system: A decade of progress, J. Geophys. Res., 103, 14 169-14240 1998.

Matsoukas, C., Banks, A. C., Hatzianastassiou, N., Pavlakis, K. G., Hatzidimitriou, D., Drakakis, E., Stackhouse, P. W., and Vardavas, I.: Seasonal heat budget of the Mediterranean Sea, J. Geophys. Res., 110, C12008, doi:10.1029/2004JC002566, 2005.

Neelin, J. D., Battisti, D. S., Hirst, A. C., Jin, F. F., Wakata, Y., Yamagata, T., and Zebiak, S. E.: ENSO theory, J. Geophys. Res., 103, 14 262-14 290, 1998.

Pavlakis, K. G., Hatzidimitriou, D., Matsoukas, C., Drakakis, E., Hatzianastassiou, N., and Vardavas, I.: Ten-year global distribution of downwelling longwave radiation, Atmos. Chem. Phys., 4, 127-142, 2004, http://www.atmos-chem-phys.net/4/127/2004/.

Philander, S. G.: El Niño, La Niña, and the Southern Oscillation, Academic Press, San Diego, CA, 1-289, 1990.

Picaut, J., Masia, F., and du Penhoat, Y.: An advective-reflective conceptual model for the oscillatory nature of the ENSO, Science, 277, 663-666, 1997.

Ramanathan, V. and Collins, W.: Thermodynamic regulation of ocean warming by cirrus clouds deduced from observations of the 1987 El Niño, Nature, 351, 27-32, 1991.

Rossow, W. B. and Schiffer, R. A.: Advances in understanding clouds from ISCCP, Bull. Am. Meteorol. Soc., 80, 2261-2288, 1999.

Suarez, M. J. and Schopf, P. S.: A delayed action oscillator for ENSO, J. Atmos. Sci., 45, 3283-3287, 1988.

Tian, B. and Ramanathan, V.: Role of tropical clouds in surface and atmospheric energy budget, J. Climate, 15, 296-305, 2002. 
Trenberth, K. E.: The Definition of El Niño, Bull. Amer. Meteorol. Soc., 78, 2771-2777, 1997.

Trenberth, K. E. and Stepaniak, D. P.: Indices of El Niño evolution, J. Climate, 14, 1697-1701, 2001.

Vardavas, I. and Carver, J. H.: Solar and terrestrial parameterizations for radiative convective models, Planet. Space Sci., 32, 1307-1325, 1984.

Wolter, K. and Timlin, M. S. : Measuring the strength of ENSO events: How does 1997/98 rank?, Weather, 53, 315-324, 1998.
Wang, C., Weisberg, R. H., and Virmani, J. I.: Western Pacific interannual variability associated with the El Niño-Southern Oscillation, J. Geophys. Res., 104, 5131-5149, 1999.

Wang, C.: A unified oscillator model for the El Niño-Southern Oscillation, J. Climate, 14, 98-115, 2001.

Wang, C.: Atmospheric circulation cells associated with the El Niño-Southern Oscillation, J. Climate, 15, 399-419, 2002.

Wang, C. and Fiedler P. C.: ENSO variability and the Eastern Tropical Pacific: A Review, Progress in Oceanography, 69, 239-266, 2006. 